\title{
RESEARCH
}

Open Access

\section{Clinicopathological features of 214 maxillary sinus pathologies. A ten-year single-centre retrospective clinical study}

Mario Pérez-Sayáns 1*, José M. Suárez Peñaranda², Juan Antonio Suárez Quintanilla³, Cintia M. Chamorro Petronacci', Abel García García ${ }^{1}$, Andrés Blanco Carrión ${ }^{1}$, Pilar Gándara Vila ${ }^{1}$ and Yolanda Guerrero Sánchez ${ }^{4}$

\begin{abstract}
Background: Diagnosis of maxillary sinus pathology must include the clinical radiological study (CRS) and histopathological analysis. The aim of this study is 1) to describe the clinicopathological features of maxillary sinus lesions, obtained successively in a single medical centre over the last 10 years and 2) to determine the sensitivity and specificity for the diagnosis of malignant lesions based exclusively on the CRS.

Methods: It is a single-centre observational retrospective clinical study on patients who attended the University Hospital Complex of Santiago de Compostela (CHUS) with sinus pathologies during the period of 2009-2019.

Results: The sample consisted of 133 men (62.1\%) and 81 women (37.9\%), with an average age of 46.9 years (SD = 18.8). In terms of frequency, the most frequent pathology was the unspecified sinusitis (44.4\%), followed by polyps (18.2\%), malignant tumours (9.8\%), inverting papilloma (7.5\%), fungal sinusitis (4.7\%), cysts (3.7\%), benign tumours (2.3\%), mucocele (2.3\%) and other lesions (1.9\%). Cysts and benign tumours were diagnosed earliest Vs malignant tumours (65.2 years $(S D=16.1)$ ) were diagnosed the latest $(p<0.001)$. Based only on the CRS for malignancies, diagnostic indexes were $71.4 \%$ sensitivity and $97.9 \%$ specificity, with a Kappa value of 0.68 with $(p<0.001)$.
\end{abstract}

Conclusion: Maxillary sinus pathology is very varied with therapeutic and prognostic repercussions. CRS is sometimes insufficient and histopathological confirmation is essential.

Keywords: Maxillary sinus pathology, Malignant tumours, Clinic radiological study, Histopathology, Diagnostic indexes

\footnotetext{
* Correspondence: perezsayans@gmail.com

${ }^{1}$ Health Research Institute of Santiago (IDIS), Oral Medicine, Oral Surgery and Implantology Unit (MedOralRes), Faculty of Medicine and Dentistry, University of Santiago de Compostela, C.P. 15782 Santiago de Compostela, Spain

Full list of author information is available at the end of the article
}

(c) The Author(s). 2020 Open Access This article is licensed under a Creative Commons Attribution 4.0 International License, which permits use, sharing, adaptation, distribution and reproduction in any medium or format, as long as you give appropriate credit to the original author(s) and the source, provide a link to the Creative Commons licence, and indicate if changes were made. The images or other third party material in this article are included in the article's Creative Commons licence, unless indicated otherwise in a credit line to the material. If material is not included in the article's Creative Commons licence and your intended use is not permitted by statutory regulation or exceeds the permitted use, you will need to obtain permission directly from the copyright holder. To view a copy of this licence, visit http://creativecommons.org/licenses/by/4.0/ The Creative Commons Public Domain Dedication waiver (http://creativecommons.org/publicdomain/zero/1.0/) applies to the data made available in this article, unless otherwise stated in a credit line to the data. 


\section{Introduction}

The maxillary sinus is a pyramid-shaped structure with its base pointing towards the nasal sidewall and its apex pointing towards the zygomatic process of the maxilla. It contains an ostium which is located towards the cranial side and which connects it to the middle meatus of the nasal cavity, thus enabling the drainage of its content [1]. Its location and distribution facilitates combined sinus pathology (pan-sinus involvement) and conditions the participation of very diverse medical specialists: maxillofacial surgeons, otorhinolaryngologists, odontologists and also allergists [2].

Among the diseases that affect it, anatomical conditions such as aplasia or hypoplasia of the maxillary sinus, nonspecific and specific infectious and inflammatory processes, and allergic and tumoral pathologies can be highlighted. Prior to undertaking a surgical intervention on the maxillary sinus and in order to avoid any possible complications, it is very important to evaluate it using diagnostic imaging techniques, by performing a clinical radiological study (CRS) [3] On many occasions, the histopathological study is fundamental in determining a definitive diagnosis, allowing for a correct therapeutic attitude [4].

Inflammatory processes, generically known as sinusitis, are the most frequent sinus pathologies. Sinusitis is classified into five categories: acute maxillary sinusitis, recurring acute sinusitis, subacute sinusitis, chronic sinusitis and acute exacerbation of chronic sinusitis, which may be specific (e.g., fungal) or non-specific. In some cases, patients suffer from chronic asymptomatic inflammatory processes with an unknown aetiology and an abrupt onset which consist of infectious and/or obstructive pathologies. Less frequently cysts, mucoceles, antrochoanal polyps and benign and malignant tumours might appear [2].

The aim of this study is 1) to describe the findings and clinicopathological features of 214 maxillary sinus lesions, obtained successively in a single medical centre over the last 10 years and 2) to determine the sensitivity and specificity for the diagnosis of malignant lesions based exclusively on the CRS.

\section{Material and methods}

\section{Selections of patients}

It is a single-centre observational retrospective clinical study on patients who attended the University Hospital Complex of Santiago de Compostela (CHUS) with sinus pathologies during the period of 2009-2019. All of the procedures performed in this study complied with the ethical standards established by the institutional and research committee and with the Declaration of Helsinki of 1964 and its subsequent amendments. All of the patients gave written or verbal consent to participate in the study and likewise they granted their permission for the research results to be published anonymously. This study received the approval of the Galician Clinical Research Ethics Committee (Ref. 2019/596). It was conducted in accordance with the STROBE guidelines for observational studies.

\section{Inclusion and exclusion criteria}

The inclusion criteria were: patients of any age and gender who attended a medical consultation due to a paranasal sinus pathology and who required at least a confirmatory biopsy or surgical treatment of the lesion. The exclusion criteria were: patients who had not given informed consent, patients with lesions localised in a region other than the maxillary sinus (see ethmoid sinus, sphenoidal or nostril), relapses of previously diagnosed and/or treated lesions, new lesions in the same patient, lesions which affect the maxillary sinus due to locoregional spreading but which originate in another location, and infectious lesions with odontogenic origin.

\section{Study variables}

The following variables were collected from the study: birth dates, dates of diagnosis, sex, suspected clinical diagnosis, radiological technique (CT or CBCT) and histologically confirmed diagnosis. The clinical diagnosis was determined according the physician's criteria and was based on clinical and semiological findings and radiological data. The radiological techniques used were cone beam computed tomography (CBCT) and classical computerized tomography on a case-by-case basis. Clinical diagnosis was comprised of: unspecified sinusitis, fungal sinusitis, inverting papilloma, polyp, cyst, mucocele, benign tumours, malignant tumours and others. The histopathological diagnosis allowed for clinical confirmation and made it possible for the origin of the inflammatory/infectious process, the histologic type of the tumour, and/or other clinically undetermined pathologies to be determined in a more specific manner.

\section{Radiological study}

All CBCTs were performed using the same equipment: Planmeca ProMax 3-D Max; Planmeca Oy, Helsinki, Finland). The radiographs were obtained with the patient in the same position and the beam emission parameters were $\mathrm{kV}=96, \mathrm{~mA}=8$, exposure time of $12 \mathrm{~s}$ with an image size of 466 voxels (each voxel equals 200 $\mathrm{mm}$ ). The evaluation software used was Romexis 2.5.1 R (Planmeca Oy, Helsinki, Finland), which allowed observing the data in multiple windows where the axial, coronal and sagittal planes could be visualized in $0.2 \mathrm{~mm}$ intervals. The study includes patients from the last 10 years, so the initial radiological tests corresponded to CT that was the device available in the service and once the CBCT was implanted, it was used. All CTs were 
performed using the Somatom Sensation Open equipment, Siemens, Forchheim, Germany; voxel size: $1.0 \times$ $1.0 \times 2.0 \mathrm{~mm}$; scan voltage: $130 \mathrm{kV}$; and convolution kernel: B30).

\section{Histopathological study}

This was conducted in a routine manner with paraffin inclusion and hematoxylin and eosin stain. Where necessary, multiple sections of each of the blocks were made and PAS and Grocott stains were used in those patients whose clinical suspicion included a micosis. The tumours were classified and studied according the WHO Classification of Head and Neck Tumours and the AJCC criteria (7th and 8th Edition, according the year of diagnosis). When necessary, an immunohistochemical study was performed in order to classify the neoplasms.

\section{Definitive diagnosis}

The definitive diagnosis of tumor pathology based on the CRS is complex and depends on the specialist physician. The decision tree was based on anamnesis, clinical manifestations, and radiological findings. Briefly, the main symptoms of non-tumor pathology included: pain and pressure behind the eyes, nasal discharge and congestion, partial or total loss of the sense of smell, fatigue and general ill feeling, headache or headache, fever, pain throat and drip between the nose and pharynx and sometimes cough. This symptomatology had to be accompanied by the following radiological findings: total or partial veiling of one or more sinuses, intra-sinusal fluid levels, and thickening of the mucosa. In the chronic inflammatory forms, retention cysts, polyps, mucoceles and sometimes images of fungal balls were associated. Tumor pathology was suspected with the existence of: obstructed paranasal sinuses that were not uncovered or with pressure, headache, runny nose and especially bleeding, ulcers inside the nose that did not heal, masses on the face, palate or nose, numbness or tingling in the face, swelling in the eyes or diplopia and pain or mobility in the maxillary teeth. These manifestations had to be accompanied by radiological findings in the form of expansive lesions with soft tissue density, signs of erosion, remodelling and / or destruction of the bone walls. These findings constituted the CRS and conferred a suspected diagnosis that was confirmed by biopsy and histopathological study. Hematoxylin-eosin staining and PAS staining for fungi were routinely performed, and in the case of malignant or highly undifferentiated lesions, immunohistochemistry was used with different epithelial, connective or hematopoietic markers depending on the histological lineage.

The initial suspected diagnosis was only based on the clinical and radiological evaluation (CRS). In case of several possible diagnoses, for the main objective of the study (to differentiate between benign and malignant lesions), it was always considered the worst of suspected diagnoses, evaluating the possibility of malignancies in a dichotomous way (yes or not). The definitive diagnosis was made by the clinical physician based on the results of the anamnesis and the clinical examination, the specific radiological findings on $\mathrm{CT} / \mathrm{CBCT}$ and the anatomopathological report.

\section{Statistical analysis}

The evaluation has been made basing on the unit of measurement "patient", since all the patients had only one lesion in the moment of diagnosis. The descriptive statistic was performed using frequencies and percentages for the categorical variables and averages and standard deviations for the quantitative variables. The Kolmogorov-Smirnov test was used to verify the normality of age variance. Contingency tables were drawn up using the Chi-squared test. The analytical statistic was performed by comparing the variables using the ANOVA test for independent samples. Cohen's Kappa index was calculated to determine the degree of agreement between the clinical and histopathological diagnosis. All of the divergences in which the value of $\mathrm{p}$ was less than or equal to 0.05 were considered to be statistically significant. The SPSS 23.0 statistics software was used.

\section{Results}

The analysed sample was comprised of 214 maxillary sinus lesions belonging to 133 men (62.1\%) and 81 women (37.9\%), with an average age of 46.9 years $(\mathrm{SD}=$ 18.8) and an age range from 2.7 to 92.5 . A summary of the sample data can be found in Table 1. In terms of frequency, the most frequent pathology was the unspecified sinusitis $(44.4 \%)$, followed by polyps $(18.2 \%)$, malignant tumours $(9.8 \%)$, inverting papilloma (7.5\%), fungal sinusitis $(4.7 \%)$, cysts $(3.7 \%)$, benign tumours $(2.3 \%)$, mucocele $(2.3 \%)$ and other lesions (1.9\%). There were no differences regarding gender and clinical diagnoses.

Fungal sinusitis included: five mucormycosis, five aspergillosis and ten unknown fungus balls (requiring a specific microbiological study). Benign tumours proved infrequent (2.3\%) with the following distribution: one fibrolipoma, one cavernous hemangioma, one cystic ameloblastoma and two osteomata. Malignant tumours represented almost $10 \%$ of the sample with $52.4 \%$ carcinomas, $26.6 \%$ adenocarcinomas and $14.3 \%$ lymphomas of different histological subtypes and to a lesser extent esthesioneuroblastoma and a metastasis of clear cell renal tumour (Table 2). Other lesions included: a case of maxillary sinus mucosa with fibrosis and vascular congestion (mucosal thickening), a hyperostosis, an organized clot, and a case of non-necrotizing granulomatosis with polyangiitis. Figures 1 and 2, show the most 
Table 1 Summary of the sample data. *Chi-square test for the comparison

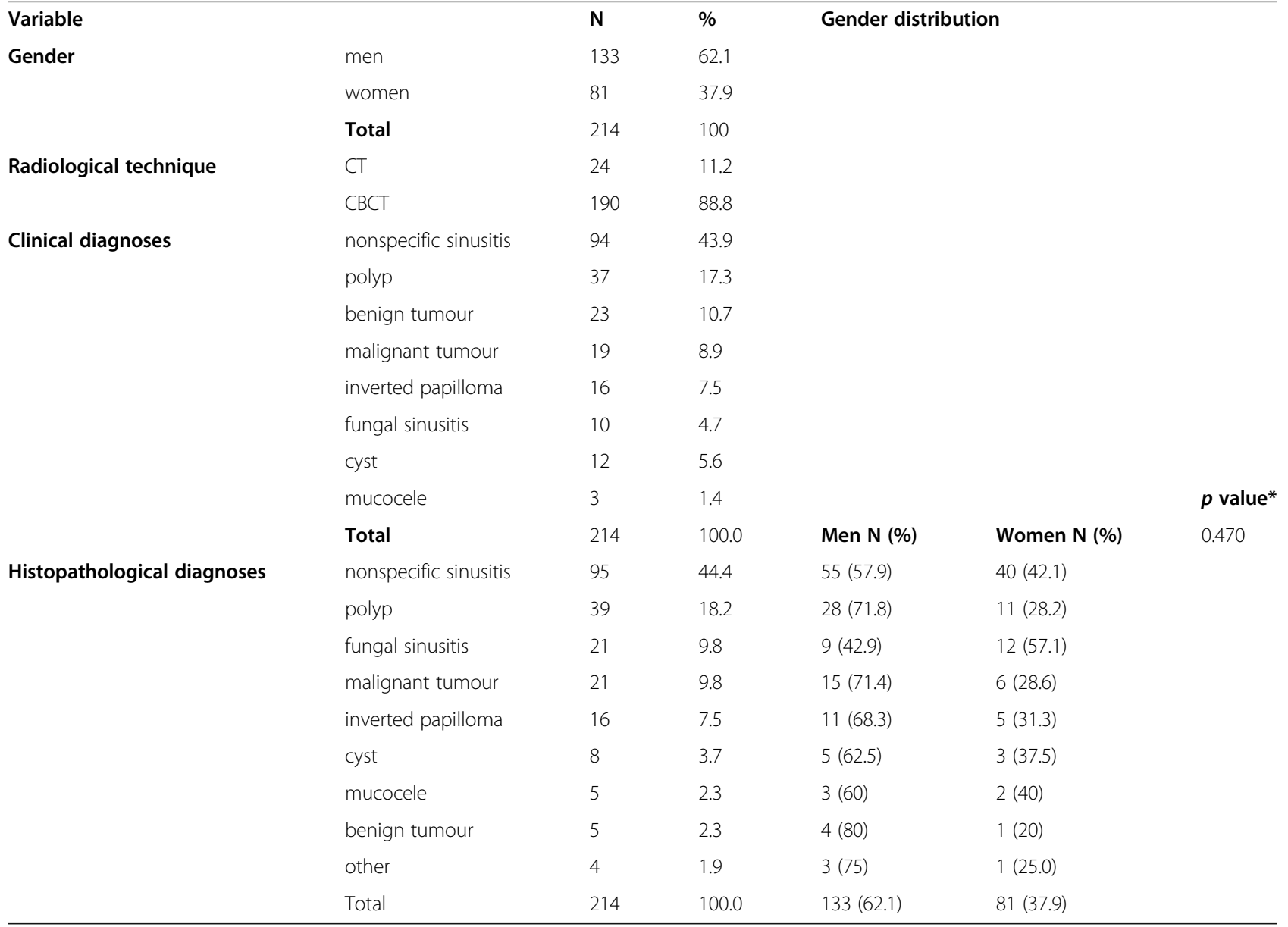

Table 2 Description of histological types of benign and malignant tumours and other lesions

\begin{tabular}{ll}
\hline Lesion & Histological Type \\
\hline Benign tumours (87.9\%) & 1 fibrous lipoma \\
& 1 cavernous haemangioma \\
Malignant tumours (9.8\%) & 1 cystic ameloblastoma \\
& 2 osteomas \\
& 9 sinonasal epidermoid carcinoma (6 undifferentiated) \\
& 5 enteric-type mucinous adenocarcinomas \\
& 2 diffuse large B-cell lymphoma \\
& 1 NKT lymphoma, nasal type \\
& 1 cystic adenoid carcinoma \\
& 1 basal-cell carcinoma \\
& 1 carcinosarcoma \\
Other lesions (2.3\%) & 1 Esthesioneuroblastoma \\
& 1 metastasis of clear-cell renal tumour \\
& 1 Mucosal thickening \\
& 1 Hyperostosis \\
\hline & 1 Organised haematoma \\
& 1 Non-necrotising granulomatosis (granulomatosis with polyangiitis (GPA)) \\
\hline
\end{tabular}




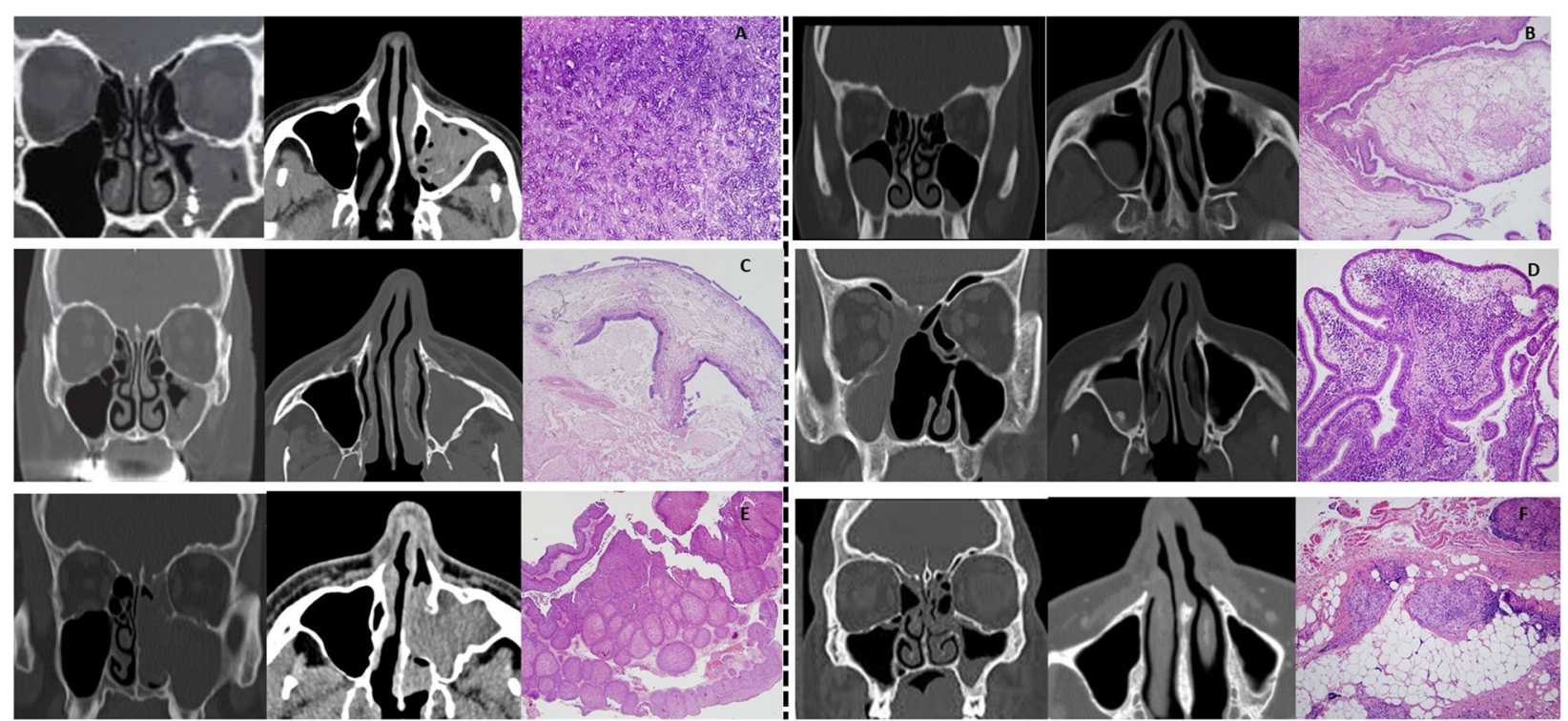

Fig. 1 Non-tumoral pathology affecting maxillary sinus, showing the main radiological and the histopathological aspects. a Mucormycosis. b Retention cyst. c Mucocele. d Polyp. e Inverted papilloma. f Non-necrotising granulomatosis. From left to right: coronal/axial sections and histopathology with hematoxylin-eosin

representative lesions of non-tumoral and tumoral pathology affecting maxillary sinus, showing the main radiological and the histopathological aspects.

There are statistically significant divergences with regards to the average age of diagnosis of the different diseases $(p<0.001)$. Cysts and benign tumours were diagnosed earliest while the malignant tumours were diagnosed the latest. By applying post hoc tests using the Bonferroni test verified with Sidak, significant differences between some specific diseases were confirmed (Table 3). It should be noted that the average age of patients with malignant tumours was $65.2(\mathrm{SD}=16.1)$, higher than the average age of patients with unspecified sinusitis (42.6, $\mathrm{SD}=17.7)$, polyps $(42.6, \mathrm{SD}=16.7)$ and cysts $(38.6, \mathrm{SD}=$ 17.2).

When the degree of agreement and concordance between the clinical and histopathological diagnosis was analysed, a Kappa value of 0.68 with $p<0.001$ was

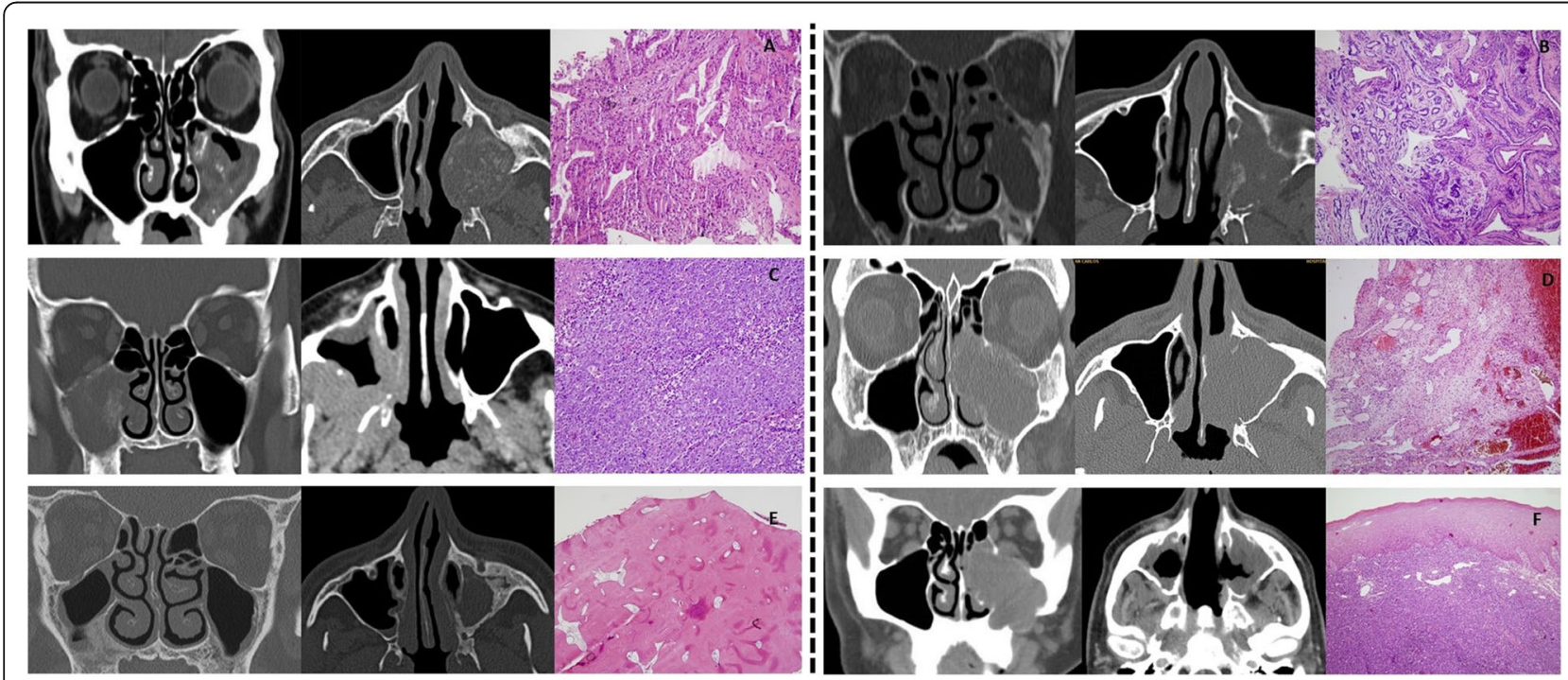

Fig. 2 Tumoral pathology (benign and malignant) affecting maxillary sinus, showing the main radiological and the histopathological aspects. a Adenocarcinoma. b Cystic adenoid carcinoma. c Lymphoma. d Haemangioma e Osteoma. f Esthesioneuroblastoma. From left to right: coronal/ axial sections and histopathology with hematoxylin-eosin 
Table 3 Divergences with regards to the average age of diagnosis of the different diseases. NS: non-significant. $N=$ number. SD = standard deviation

\begin{tabular}{|c|c|c|c|c|c|c|}
\hline Age & $\mathbf{N}$ & Average & SD & Minimum & Maximum & Significant differences \\
\hline Non-specific sinusitis & 95 & 42.6 & 17.7 & 2.9 & 74.9 & $\begin{array}{l}\text { Fungal sinusitis } p=0.014 \\
\text { Malignant tumour } p<0.001\end{array}$ \\
\hline Fungal sinusitis & 21 & 57.5 & 17.4 & 20.3 & 92.5 & Nonspecific sinusitis $p=0.014$ \\
\hline Inverted papilloma & 16 & 56.1 & 11.0 & 37.8 & 78.0 & NS \\
\hline Polyp & 39 & 42.6 & 16.7 & 7.4 & 71.4 & Malignant tumour $p<0.001$ \\
\hline Cyst & 8 & 38.6 & 17.2 & 18.8 & 58.2 & Malignant tumour $p=0.009$ \\
\hline Mucocele & 5 & 41.6 & 26.1 & 3.6 & 66.7 & NS \\
\hline Benign tumour & 5 & 38.8 & 24.1 & 2.7 & 70.2 & NS \\
\hline Malignant tumour & 21 & 65.2 & 16.1 & 16.3 & 87.4 & $\begin{array}{l}\text { Nonspecific sinusitis } p<0.001 \\
\text { Polyp } p<0.001 \\
\text { Cyst } p=0.009\end{array}$ \\
\hline Other & 4 & 41.2 & 10.9 & 32.0 & 53.7 & NS \\
\hline Total & 214 & 47.0 & 18.8 & 2.7 & 92.5 & $P<0.001$ \\
\hline
\end{tabular}

obtained, reflecting a high, but not infallible rate of clinical success. Among the errors, a case of inverting papilloma and five clinical and radiological benign tumours which ended up being malignant lesions are worth mentioning (Table 4). Based on the clinical and radiology methods alone for the definitive diagnosis of malignancy, we obtained a true positives rate of $78.9 \%$, a false positives rate of $21.1 \%$, a false negatives rate of $8.9 \%$ and a true negatives rate of $91.1 \%$. The diagnostic indexes were $71.4 \%$ sensitivity and $97.9 \%$ specificity. There were no differences regarding the radiological technique (CT or $\mathrm{CBCT})$ and the diagnostic accuracy $(p>0.05)$.

\section{Discussion}

In this study, we analysed the prevalence of different diseases affecting the maxillary sinus for a period of ten consecutive years in a reference university hospital for otolaryngologists and maxillofacial surgeons. The results confirmed the existence of a wide range of diseases with different origins and complexity, not only in terms of diagnosis, but also in terms of prognosis. Clinical and radiological analyses are not always sufficient for an accurate diagnosis. For this reason, the histopathological study is mandatory. A radiological study must be performed using a CT/CBCT and not a panoramic x-ray since it offers less diagnostic sensitivity [3].

Table 4 Degree of agreement and concordance between the clinical and final histopathological diagnosis

\begin{tabular}{|c|c|c|c|c|c|c|c|c|c|c|c|}
\hline & & \multicolumn{9}{|c|}{ Histopathological Diagnosis } & \multirow[t]{2}{*}{ Total } \\
\hline & & $\begin{array}{l}\text { Nonspecific } \\
\text { sinusitis }\end{array}$ & $\begin{array}{l}\text { Fungal } \\
\text { sinusitis }\end{array}$ & $\begin{array}{l}\text { Inverted } \\
\text { papilloma }\end{array}$ & Polyp & Cyst & Mucocele & $\begin{array}{l}\text { Benign } \\
\text { tumour }\end{array}$ & $\begin{array}{l}\text { Malignant } \\
\text { tumour }\end{array}$ & Other & \\
\hline \multirow[t]{8}{*}{$\begin{array}{l}\text { Clinical } \\
\text { diagnosis }\end{array}$} & $\begin{array}{l}\text { Non-specific } \\
\text { sinusitis }\end{array}$ & $79(84.0 \%)$ & $11(11.7 \%)$ & 0 & $\begin{array}{l}4 \\
(4.3 \%)\end{array}$ & 0 & 0 & 0 & 0 & 0 & $\begin{array}{l}94 \\
(100 \%)\end{array}$ \\
\hline & $\begin{array}{l}\text { Fungal } \\
\text { sinusitis }\end{array}$ & $2(20 \%)$ & $8(80 \%)$ & 0 & 0 & 0 & 0 & 0 & 0 & 0 & $\begin{array}{l}10 \\
(100 \%)\end{array}$ \\
\hline & $\begin{array}{l}\text { Inverted } \\
\text { papilloma }\end{array}$ & 0 & 0 & $13(81.3 \%)$ & $\begin{array}{l}2 \\
(12.5 \%)\end{array}$ & 0 & 0 & 0 & $1(6.3 \%)$ & 0 & $\begin{array}{l}16 \\
(100 \%)\end{array}$ \\
\hline & Polyp & $3(8.1 \%)$ & 0 & $3(8.1 \%)$ & $\begin{array}{l}29 \\
(78.4 \%)\end{array}$ & $\begin{array}{l}1 \\
(2.7 \%)\end{array}$ & 0 & 0 & 0 & $\begin{array}{l}1 \\
(2.7 \%)\end{array}$ & $\begin{array}{l}37 \\
(100 \%)\end{array}$ \\
\hline & Cyst & $4(33.3 \%)$ & 0 & 0 & 0 & $\begin{array}{l}7 \\
(58.3 \%)\end{array}$ & $1(8.3 \%)$ & 0 & 0 & 0 & $\begin{array}{l}12 \\
(100 \%)\end{array}$ \\
\hline & Mucocele & 0 & 0 & 0 & 0 & 0 & $3(100.0 \%)$ & 0 & 0 & 0 & $\begin{array}{l}3 \\
(100 \%)\end{array}$ \\
\hline & $\begin{array}{l}\text { Benign } \\
\text { tumour }\end{array}$ & $4(17.4 \%)$ & $2(8.7 \%)$ & 0 & $\begin{array}{l}4 \\
(17.4 \%)\end{array}$ & 0 & $1(4.3 \%)$ & $5(21.7 \%)$ & $5(21.7 \%)$ & $\begin{array}{l}2 \\
(8.7 \%)\end{array}$ & $\begin{array}{l}23 \\
(100 \%)\end{array}$ \\
\hline & $\begin{array}{l}\text { Malignant } \\
\text { tumour }\end{array}$ & $3(15.8 \%)$ & 0 & 0 & 0 & 0 & 0 & 0 & 15 (78.9\%) & $\begin{array}{l}1 \\
(5.3 \%)\end{array}$ & $\begin{array}{l}19 \\
(100 \%)\end{array}$ \\
\hline Total & & 95 (44.4\%) & 21 (9.8\%) & $16(7.5 \%)$ & $\begin{array}{l}39 \\
18.2 \%)\end{array}$ & $\begin{array}{l}8 \\
(3.7 \%)\end{array}$ & $5(2.3 \%)$ & $5(2.3 \%)$ & 21 (9.8\%) & $\begin{array}{l}4 \\
(1.9 \%)\end{array}$ & $\begin{array}{l}214 \\
(100 \%)\end{array}$ \\
\hline
\end{tabular}


Drumond and Cols [5] performed a study exclusively using a CT in order to evaluate the prevalence of different illnesses in 762 maxillary sinuses. They found that 305 examinations $(40.02 \%)$ were normal and 457 examinations (59.97\%) were abnormal: focal mucoperiosteal thickening (21.25\%), polypoid lesions (10.76\%), chronic sinusitis (7.48\%); chronic odontogenic sinusitis (2.29\%); neoplasms (2.03\%); rhinosinusitis (1.77\%); bone lesions, foreign bodies and oroantral fistula in $0.65 \%$; 0.13 and $0.06 \%$ respectively. Our study verified that the diagnostic sensitivity using CRS exclusively in maxillary sinus disease is $70 \%$. In terms of using CBCT or CT for diagnostic accuracy, we did not find any difference. This matter has been confirmed by other authors [6].

Rhinosinusitis is defined as the inflammation of the nose and sinuses and it is considered as one of the most frequent diseases in humans, affecting $5-10 \%$ depending on the origin of the population. Most of them are inflammatory and/or unspecified allergic and in our paper they represent almost half of all the lesions studied (44.4\%). In our study we excluded sinusitis of dental origin, but it must be mentioned that these can account for $10-20 \%$ of all chronic sinusitis More than $95 \%$ of the sinusitis (including unspecific and fungal) were properly diagnosed using CRS [7].

The second most frequent disease was polyps (18.2\%), included within what is known as antrochoanal polyps (ACP). ACPs are benign lesions which emerge in the maxillary sinus mucosa and reach the choana, and the main symptom of these is nasal obstruction [8]. Men tend to suffer more from this disorder (18.2\%) and the average age of diagnosis is 42.6 years, however there is a wide age range from 7.4 to 71.4 years. $7.8 \%$ of our cases were under the age of 18 , coinciding with the results of Segal et al. [9]. 80\% were diagnosed using CRS, however $8.1 \%$ turned out to be inverted papillomas, so the pathological anatomical confirmation is very important due to the different nature of this lesion and its tendency to relapse if not properly removed [10]. No differences have been found in term of gender.

A specific kind of sinusitis is the fungal sinusitis, which represented $9.8 \%$ of cases in our study. In the CRS these are described as fungus balls in order to differentiate them from mycetomas, as a tropical disease [11-15]. Mucormycosis [16] and aspergillosis [17] are among the most frequent specific entities. According to Pagella and Cols [12] only $34.5 \%$ of the cases with fungal hyphae present in the biopsy were microbiologically positive in the culture. $100 \%$ of the lesions with non-invasive fungus balls presented hyphae in the anatomopathological study. Non-invasive lesions are more serious with an associated risk of systemic involvement [14], however, in our study we did not find any such case. According to Lim and Cols [15] the average age of diagnosis is 63.1 years with significant female predominance; this data was confirmed by Yoon et al. in a study of 538 sinus fungus balls [13]. In our study, $57.1 \%$ were women and the average age was 57.5 years. The most common etiologic organism of this disease is Aspergillus fumigatus, an ubiquitous dimorphic fungus that causes several types of lung disease. In non-invasive aspergillosis, the fungus colonizes a pre-existing cavity and forms a fungus ball consisting of compact concentric hyphae. The demonstration of hyphae and the lack of eosinophils in the mucus of these patients differentiates this condition from allergic fungal sinusitis. Its infection can coexist with other processes, such as non-specific bacterial sinusitis and less frequently with actinomyces [18]. Mucormycosis, on the other hand, is an angioinvasive fungal infection associated with high morbidity and mortality. A change in the epidemiology of mucormycosis has been observed over the past few years with an increased incidence worldwide [16].. According to Celis et al. [19] the average age was 53.14 years. Four patients were immunosuppressed and three were immunocompetent. Indolent mucormycosis is a new and emerging clinical entity in immunosuppressed and also immunocompetent patients. The single paranasal presentation is infrequent and should not be overlooked as a differential diagnosis.

Sinonasal tumours are rare neoplasms. The diagnosis and treatment of these tumours poses several challenges due to their low incidence, histological diversity, and the production of nonspecific symptoms in the early stages. In this study, the neoplastic pathology of the maxillary sinus, contrary to expectations, was very frequent, with the malignant tumours (9.8\%) surpassing the benign ones $(2.3 \%)$. The most common types were epidermoid carcinoma and adenocarcinoma (Table 3). More than $80 \%$ of the carcinomas were poorly differentiated, coinciding with the data from Banuchi and Cols' [20] and Santos and Cols' [21] studies. The CRS does not allow for the diagnosis or pattern of invasion to be clearly determined [22]. The therapeutic management is complex and requires surgery, chemotherapy and radiotherapy, offering a reserved prognosis [23] Other histological varieties were lymphomas, mostly histological subtype $\mathrm{B}$, although we also found a case of nasal type T/NK lymphoma, the most common varieties in this location. Within the head and neck, the majority of the extranodal lymphomas emerge in the Waldeyer ring; comprised of the adenoid tonsils, Eustachian tonsils, palatal tonsils, and lingual tonsils, although other commonly involved sites include the nasal cavity and sinuses [24, 25]. An important histological subtype is the adenoid cystic carcinoma (Table 3), (old cylindroma) which, although it tends to have a predilection for the head and neck, actually represents less than $2 \%$ of malignant tumours of the head and neck and 5 to $15 \%$ of paranasal sinus although 
it has a high capacity for local infiltration [26, 27]. Esthesioneuroblastoma is a rare neoplasm that arises from the nasal cavity's olfactory neuroepithelium. It shows bimodal age distribution, with peaks from the second to the third, as well as from the sixth to the seventh, decades of life [28]. In our case it was a 39-year-old male. Metastases are rare, but they can occur. The most common metastases originate in the kidney, breast, thyroid and prostate, although they have been described as originating in multiple locations [4]. In our series, we found a metastasis of clear cell renal carcinoma, which appears to be the histological subtype with greatest predilection to cause metastases in the maxillary sinus [29,30].

The inverted papilloma is a rare neoplasm preferably located in the lateral nasal wall, it is characterized by its relapse tendency, and its potential transformation into malignant neoplasms [31]. In our study, it was the fifth most frequent pathology present in $7.5 \%$ of the cases and it was more prevalent in men $(68.3 \%)$ with an average age of 56 years. Although lesion recurrences were excluded from the study, we observed a recurrence in more than $60 \%$ of the cases. Diaz Molina et al. [31], found similar results in which $62 \%$ of cases were male with an average age of 58 years. Adriansen and Cols [32]., uncovered similar results with an average age of 47.8 years and $71.4 \%$ of cases were male. The CRS follow-up of these patients should be very close.

A more varied group of diseases of high diagnostic complexity by CRS are those known as cysts, pseudocysts and mucoceles. Basically, mucoceles are (cyst-like) structures covered with epithelium and filled with mucin, produced by the obstruction of the drainage ostium, due to their destructive capacity these usually cause pain [33] Retention cysts, on the other hand, have a linear epithelial cystic structure that does not cause destruction and these are caused by alterations in the homeostatic balance of the mucosa. The average patient age is around 40 years old in both cases and predominantly male, coinciding with Veltrini and Cols' findings [34].

Benign tumours were the least prevalent group: fibrolipoma, cavernous haemangioma, cystic ameloblastoma, and two osteomata. Benign tumours presented greater diagnostic difficulty using CRS, $17.4 \%$ were non-specific sinusitis, $17.4 \%$ polyps, $8.7 \%$ fungal sinusitis, $4.3 \%$ mucocele and $8.7 \%$ other lesions, but the most remarkable fact is that almost $22 \%$ of clinically suspected lesions were confirmed as malignant neoplasms (Table 3). Lipomas in the maxillofacial territory are rare, and the site of predilection is the mucosa of the oral cavity as we have previously reported [35], nonetheless, the maxillary sinus can host these as well [36]. Here we present a case of a seven-year-old boy, histological subtype fibrolipoma. Haemangioma is a common benign vascular lesion of the head and neck region. The mucous membranes of the nasal cavity and paranasal sinuses are rarely implicated [37], although the cavernous variety has been previously published [38]. In our series there is only one case, a 38-year-old male, whose CRS did not provide accurate information. Odontogenic tumours are lesions that are derived from the epithelium, ectomesenquim or mesenchymal components that form part of the dental development apparatus. These tumours are located centrally (intraosseous) within the jaws or peripheral (extraosseous), located inside the gingival mucosa, alveolar or less frequently the maxillary sinus [39]. The ameloblastoma is a common odontogenic tumour of the jaw which is comprised of three variants: conventional (solid), unicystic and peripheral ameloblastomas. The unicystic ameloblastoma in the maxillary sinus is very rare; we present a case of a 73-year-old male, which differs from the few cases published in the literature in which the age of diagnosis is younger [40]. Osteoma is a benign tumour composed of well-differentiated bone tissue with laminar structure, located in bones or soft tissues. Osteomata mainly occur in the head and neck region, especially in the jaw and paranasal sinuses, which is the most common benign tumour of the paranasal sinuses [41, 42].. Among our cases, there was only one 70year-old male with typical histopathological features who was diagnosed in the CRS.

We have included a group of lesions, framed as "other lesions": 1) opacification, fibrosis and mucosal thickening, which is the most frequent radiological finding of the maxillary sinus [41], but which in our case was diagnosed as a polyp in the CRS; 2) a hyperostosis, which was confused with a benign tumour and which tend to be normal anatomical variations [43];3) an organized hematoma that was suspected to be malignant in a patient with chronic myeloid leukemia and that has been recently described [44]; 4) non-necrotizing granulomatous disease in a 33-year-old woman as part of a clinical picture of eosinophilic granulomatosis with polyangitis, an autoimmune systemic disease manifesting as asthma, recurrent sinusitis and peripheral eosinophilia [45].

\section{Conclusions}

The pathology of the maxillary sinus is very varied and it has very different therapeutic and prognostic repercussions, so its correct characterization is essential. As we have proven, CRS is sometimes insufficient and histopathological confirmation is essential.

\section{Acknowledgements \\ N/A}

Authors' contributions

M.P-S, JA.S-Q and J.G-S: methodology; C.M.C-P. and A.G-G: writing-original draft preparation; P.G-V and A.B-C: writing-review and editing; JM.S-P and J.G-S: supervision and project administration. The author(s) read and approved the final manuscript. 


\section{Funding}

This paper is partially supported by Ministerio de Ciencia, Innovación y Universidades grant number PGC2018-097198-BI00 and Fundación Séneca de la Región de Murcia grant number 20783/PI/18.

\section{Availability of data and materials}

The datasets used and/or analysed during the current study are available from the corresponding author on reasonable request.

\section{Ethics approval and consent to participate}

all procedures performed in studies involving humans were in accordance with the ethical standards of the institution or practice at which the studies were conducted (Galician Clinical Research Ethics Committee, Ref. 2019/596).

\section{Consent for publication}

Informed consent was obtained from all individual participants included in the study.

\section{Competing interests}

The authors declare that they have no competing interests.

\section{Author details}

${ }^{1}$ Health Research Institute of Santiago (IDIS), Oral Medicine, Oral Surgery and Implantology Unit (MedOralRes), Faculty of Medicine and Dentistry, University of Santiago de Compostela, C.P. 15782 Santiago de Compostela, Spain. ${ }^{2}$ Pathological Anatomy Service, University Hospital Complex of Santiago (CHUS), C.P. 15782 Santiago de Compostela, Spain. ${ }^{3}$ Area of Human Anatomy and Embryology, Faculty of Medicine and Dentistry, University of Santiago de Compostela, C.P. 15782 Santiago de Compostela, Spain. ${ }^{4}$ Area oh Human Anatomy and Psychobiology, University of Murcia, Murcia, Spain

\section{Received: 23 March 2020 Accepted: 1 October 2020}

Published online: 13 October 2020

\section{References}

1. Whyte A, Boeddinghaus R. The maxillary sinus: physiology, development and imaging anatomy. Dentomaxillofac Radiol. 2019;48(8):20190205. https:// doi.org/10.1259/dmfr.20190205

2. Dykewicz MS, Hamilos DL. Rhinitis and sinusitis. J Allergy Clin Immunol. 2010;125(2 Suppl 2):103.

3. Constantine S, Clark B, Kiermeier A, Anderson PP. Panoramic radiography is of limited value in the evaluation of maxillary sinus disease. Oral Surg Oral Med Oral Pathol Oral Radiol. 2019:127(3):237-46.

4. López F, Devaney KO, Hanna EY, Rinaldo A, Ferlito A. Metastases to nasal cavity and paranasal sinuses. Head Neck. 2016;38(12):1847-54

5. Drumond JPN, Allegro BB, Novo NF, de Miranda SL, Sendyk WR. Evaluation of the Prevalence of Maxillary Sinuses Abnormalities through Spiral Computed Tomography (CT). Int Arch Otorhinolaryngol. 2017;21(2):126-33.

6. Czerwonka L, Bissada E, Goldstein DP, Wood RE, Lam EW, Yu E, et al. Highresolution cone-beam computed tomography for assessment of bone invasion in oral cancer: Comparison with conventional computed tomography. Head Neck. 2017;39(10):2016-20.

7. Kim SM. Definition and management of odontogenic maxillary sinusitis. Maxillofac Plast Reconstr Surg. 2019 Dec;41(1):13

8. Maldonado M, Martínez A, Alobid I, Mullol J. The antrochoanal polyp. Rhinology. 2004 Dec;42(4):178-82.

9. Segal N, Gluk O, Puterman M. Nasal polyps in the pediatric population. BENT. 2012:8(4):265-7.

10. Choudhury N, Hariri A, Saleh H, Sandison A. Diagnostic challenges of antrochoanal polyps: A review of sixty-one cases. Clin Otolaryngol. 2018; 43(2):670-4.

11. Huang Z, Xu H, Xiao N, Li Y, Dong Y, Li Y, et al. Predictive Significance of Radiographic Density of Sinus Opacity and Bone Thickness in Unilateral Maxillary Sinus Mycetoma. ORL J Otorhinolaryngol Relat Spec. 2019;81(2-3):111-20.

12. Pagella F, Matti E, De Bernardi F, Semino L, Cavanna C, Marone $P$, et al. Paranasal sinus fungus ball: diagnosis and management. Mycoses. 2007 Nov;50(6):451-6.

13. Yoon $\mathrm{YH}, \mathrm{Xu}$ J, Park SK, Heo JH, Kim YM, Rha K. A retrospective analysis of 538 sinonasal fungus ball cases treated at a single tertiary medical center in Korea (1996-2015). Int Forum Allergy Rhinol. 2017;7(11):1070-5.
14. Ni Mhurchu E, Ospina J, Janjua AS, Shewchuk JR, Vertinsky AT. Fungal Rhinosinusitis: A Radiological Review With Intraoperative Correlation. Can Assoc Radiol J. 2017;68(2):178-86.

15. Lim H, Yoon YH, Xu J, Kim YM, Rha K. Isolated sphenoid sinus fungus ball: a retrospective study conducted at a tertiary care referral center in Korea. Eur Arch Otorhinolaryngol. 2017;274(6):2453-9.

16. Prakash H, Chakrabarti A. Global Epidemiology of Mucormycosis. J Fungi (Basel). 2019;5(1):26. https://doi.org/10.3390/jof5010026.

17. Martins WD, Ribeiro Rosa EA. Aspergillosis of the maxillary sinus: review and case report. Scand J Infect Dis. 2004;36(10):758-61.

18. Vinay BH, Mohan A, Haritha P, Lakshmi KR. A rare coexistence of aspergillosis with actinomycosis. J Oral Maxillofac Pathol. 2017;21(2):277-81.

19. Celis-Aguilar E, Burgos-Páez A, Villanueva-Ramos N, Solórzano-Barrón J. De La Mora-Fernández A, Manjarrez-Velázquez J, et al. An Emergent Entity: Indolent Mucormycosis of the Paranasal Sinuses. A Multicenter Study. Int Arch Otorhinolaryngol. 2019;23(1):92-100.

20. Banuchi V, Mallen J, Kraus D. Cancers of the nose, sinus, and skull base. Surg Oncol Clin N Am. 2015;24(3):563-77.

21. Santos MRM, Servato JPS, Cardoso SV, de Faria PR, Eisenberg ALA, Dias FL, et al. Squamous cell carcinoma at maxillary sinus: clinicopathologic data in a single Brazilian institution with review of literature. Int J Clin Exp Pathol. 2014;7(12):8823-32.

22. Kawaguchi $M$, Kato $H$, Tomita $H$, Mizuta $K$, Aoki M, Hara A, et al. Imaging Characteristics of Malignant Sinonasal Tumors. J Clin Med. 2017;6(12):116. https://doi.org/10.3390/jcm6120116.

23. Tyler MA, Holmes B, Patel ZM. Oncologic management of sinonasal undifferentiated carcinoma. Curr Opin Otolaryngol Head Neck Surg. 2019;27(1):59-66.

24. Huang Y, Jia B, Jiang S, Zhou S, Yang J, Liu P, et al. Different clinical characteristics and treatment strategies for patients with localized sinonasal diffuse large B cell lymphoma and extranodal NK厅 cell lymphoma. J Hematol Oncol. 2017;10(1):7

25. Varelas AN, Eggerstedt M, Ganti A, Tajudeen BA. Epidemiologic, prognostic, and treatment factors in sinonasal diffuse large B -cell lymphoma. Laryngoscope. 2019;129(6):1259-64.

26. Trope M, Triantafillou V, Kohanski MA, Kuan EC, Tong CCL, Patel NN, et al. Adenoid cystic carcinoma of the sinonasal tract: a review of the national cancer database. Int Forum Allergy Rhinol. 2019;9(4):427-34.

27. Husain Q, Kanumuri W, Svider PF, Radvansky BM, Boghani Z, Liu JK, et al. Sinonasal adenoid cystic carcinoma: systematic review of survival and treatment strategies. Otolaryngol Head Neck Surg. 2013;148(1):29-39.

28. Rasool A, Dadgostar A, Manji J, Al-Asousi F, Javer A. Esthesioneuroblastoma Isolated to the Maxillary Sinus Antrum Presenting as SIADH: A Case Report. OTO Open. 2018;2(3):2473974X18792488.

29. Moffa A, Casale M, Moffa AP, Grilli G, Grilli G, Macarini L, et al. Maxillary Sinus Mass as First Presentation of Silent Metastatic Renal Cell Carcinoma. J Craniofac Surg. 2019;30(2):e135-7.

30. Bastier P, Dunion D, de Bonnecaze G, Serrano E, de Gabory L. Renal cell carcinoma metastatic to the sinonasal cavity: A review and report of 8 cases. Ear Nose Throat J. 2018 Sep;97(9):E6-E12.

31. Díaz Molina JP, Llorente Pendas JL, Rodrigo Tapia JP, Alvarez Marcos C, Obeso Agüera S, Suárez Nieto C. Inverted sinonasal papillomas. Review of 61 cases. Acta Otorrinolaringol Esp. 2009;60(6):402-8.

32. Adriaensen GFJPM, Lim K, Georgalas C, Reinartz SM, Fokkens WJ. Challenges in the Management of Inverted Papilloma: A Review of 72 Revision Cases. Laryngoscope. 2016;126(2):322-8.

33. Abdel-Aziz M, El-Hoshy H, Azooz K, Naguib N, Hussein A. Maxillary sinus mucocele: predisposing factors, clinical presentations, and treatment. Oral Maxillofac Surg. 2017;21(1):55-8.

34. Veltrini $\vee$, Ferreira Júnior O, Oliveira DT. Mucosal cysts of the maxillary sinus: a literature review. Med Oral. 2001:6(3):180-8.

35. Perez-Sayáns M, Blanco-Carrión A, Oliveira-Alves MG, Almeida JD, Anbinder AL. Lafuente-lbáñez de Mendoza I, et al. Multicentre retrospective study of 97 cases of intraoral lipoma. J Oral Pathol Med. 2019;48(6):499-504.

36. Uysal A, Kayiran O, Cuzdan SS, Bektas Cl, Aslan G, Caydere M. Maxillary sinus lipoma: an unanticipated diagnosis. J Craniofac Surg. 2007;18(5):1153-5.

37. Kim JS, Kwon SH. Sinonasal Hemangioma: Diagnosis, Treatment, and FollowUp of 37 Patients at a Single Center. J Oral Maxillofac Surg. 2017;75(8):1775-83.

38. Dutta M, Kundu S, Barik S, Banerjee S, Mukhopadhyay S. Mucosal cavernous hemangioma of the maxillary sinus. Arch Iran Med. 2015;18(2):130-2.

39. Press SG. Odontogenic tumors of the maxillary sinus. Curr Opin Otolaryngol Head Neck Surg. 2008;16(1):47-54. 
40. Pitak-Arnnop P, Chaine A, Dhanuthai K, Bertrand JC, Bertolus C. Unicystic ameloblastoma of the maxillary sinus: Pitfalls of diagnosis and management Hippokratia. 2010;14(3):217-20.

41. Kim SH, Oh JS, Incidence JYJ. Radiological Findings of Incidental Sinus Opacifications in Patients Undergoing Septoplasty or Septorhinoplasty. Ann Otol Rhinol Laryngol. 2019:3489419878453.

42. Arslan HH, Tasli H, Cebeci S, Gerek M. The Management of the Paranasal Sinus Osteomas. J Craniofac Surg. 2017;28(3):741-5.

43. Gursoy M, Erdogan N, Cetinoglu YK, Dag F, Eren E, Uluc ME. Anatomic variations associated with antrochoanal polyps. Niger J Clin Pract. 2019 May;22(5):603-8.

44. Varghese L, Mukhopadhyay S, Mehan R, Kurien R, Thomas M, Rupa V. Sinonasal organising haematoma - a little known entity. Braz J Otorhinolaryngol. 2019;85(6):698-704. https://doi.org/10.1016/j.bjorl.2018.05. 013.

45. Nakamaru Y, Takagi D, Suzuki M, Homma A, Morita S, Homma A, et al. Otologic and Rhinologic Manifestations of Eosinophilic Granulomatosis with Polyangiitis. Audiol Neurootol. 2016;21(1):45.

\section{Publisher's Note}

Springer Nature remains neutral with regard to jurisdictional claims in published maps and institutional affiliations.

Ready to submit your research? Choose BMC and benefit from:

- fast, convenient online submission

- thorough peer review by experienced researchers in your field

- rapid publication on acceptance

- support for research data, including large and complex data types

- gold Open Access which fosters wider collaboration and increased citations

- maximum visibility for your research: over $100 \mathrm{M}$ website views per year

At $\mathrm{BMC}$, research is always in progress.

Learn more biomedcentral.com/submissions 